\title{
Rete Ovarii Neoplasm
}

National Cancer Institute

\section{Source}

National Cancer Institute. Rete Ovarii Neoplasm. NCI Thesaurus. Code C40016.

A benign or malignant neoplasm that arises from the rete ovarii which is located in the ovarian hilus. It includes adenoma, cystadenoma, cystadenofibroma, and adenocarcinoma. 